Article

\title{
Carbon and Tin-Based Polyacrylonitrile Hybrid Architecture Solid Phase Microextraction Fiber for the Detection and Quantification of Antibiotic Compounds in Aqueous Environmental Systems
}

\author{
Sandip Mondal, Jialing Jiang, Yin Li and Gangfeng Ouyang * \\ MOE Key Laboratory of Bioinorganic and Synthetic Chemistry/KLGHEI of Environment and Energy Chemistry, \\ School of Chemistry, Sun Yat-sen University, Guangzhou 510275, China; sandip1706@yahoo.com (S.M.); \\ 18826133611@163.com (J.J.); yinli5@mail2.sysu.edu.cn (Y.L.) \\ * Correspondence: cesoygf@mail.sysu.edu.cn; Tel.: +86-20-84110845
}

Received: 20 March 2019; Accepted: 26 April 2019; Published: 28 April 2019

\begin{abstract}
In this study, the detection and quantification of multiple classes of antibiotics in water matrices are proposed using a lab-made solid phase microextraction (SPME) fiber coupled with high-performance liquid chromatography-tandem mass spectrometry (LC-MS/MS). The lab-made fiber was prepared using a graphene oxide $(\mathrm{G})$, carbon nanotubes $(\mathrm{C})$, and tin dioxide (T) composite, namely GCT, with polyacrylonitrile (PAN) as supporting material. The detected antibiotics were enrofloxacin, sulfathiazole, erythromycin, and trimethoprim. The custom-made fiber was found to be superior compared with a commercial C18 fiber. The excellent reproducibility and lower intra-fiber relative standard deviations (RSDs $1.8 \%$ to $6.8 \%$ ) and inter-fiber RSDs (4.5\% to $8.8 \%$ ) made it an ideal candidate for the detection of traces of antibiotics in real environmental samples. The proposed validated method provides a satisfactory limit of detection and good linear ranges with higher $(>0.99)$ coefficient of determination in the aqueous system. Application of the method was made in different real water systems such as river, pond and tap water using the standard spiking method. Excellent sensitivity, reproducibility, lower amount of sample detection and higher recovery was found in a real water sample. Therefore, the extraction method was successfully applied to the detection and quantification of multiple classes of antibiotics in different aqueous systems with satisfactory results.
\end{abstract}

Keywords: antibiotics; composite materials; solid-phase microextraction; LC-MS/MS; water matrices

\section{Introduction}

Antibiotics are a kind of antimicrobial substances produced from natural (bacterial or fungal source), semisynthetic or synthetic sources that possess the intrinsic ability of inhibiting the growth of or killing microbes [1]. Since the 1930s, antibiotics were used to treat and prevent human and veterinary animal infections and later to promote growth in livestock, poultry breeding, and aquaculture [2]. Therefore, it is not a surprising fact that they can be detected in different water bodies around the world up to $\mu \mathrm{g}$ level per liter due to the direct discharge of expired or unused medicines, metabolized drugs, the low removal efficacy of wastewater treatment plants for this class of substances and agricultural runoff [3-5]. The half-life of antibiotics is from around hours to 100 days [6], although antibiotic residues can be considered as a persistent organic contaminant in environment owing to their regular and widespread use and continual emissions [7]. Throughout the globe, the presence of antibiotics has been reported on groundwaters, surface waters and sediments [8-13]. Even at very low concentration antibiotics can exert adverse effects on ecology and human health [12,13]. The main side effects of antibiotics are the appearance of antibiotic-resistant pathogens carrying antibiotic-resistance genes 
and inhibition of the growth of aquatic organisms [14,15]. The forming antibiotic-resistant genes could invade into the human body via direct contact or food chain through horizontal gene transfer mechanism, and further antibiotic resistance causes the failure of the treatment and even death [16,17]. Therefore, monitoring and assessment of the antibiotics in a real water system is the need of this hour.

Some of the important and commonly found antibiotic residues in the environment are erythromycin, trimethoprim, enrofloxacin, and sulfathiazole. Erythromycin belongs to the macrolide antibiotic class. It can be used to treat eye infections caused by bacteria [18]. Trimethoprim is a synthetic dihydrofolate reductase inhibitor used to treat certain kind of bacterial infections such as urinary tract infections [19]. Enrofloxacin is a synthetic, broad-spectrum antibiotic that belongs to the fluoroquinolones class. This antibiotic is used to treat bacterial infections in veterinary animals [20]. Sulfathiazole is a short-acting sulfonamide used primarily in veterinary medicine [21]. The structures of these antibiotics are presented in Figure 1.

(A)

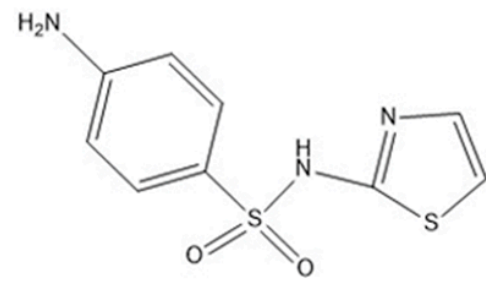

(C)

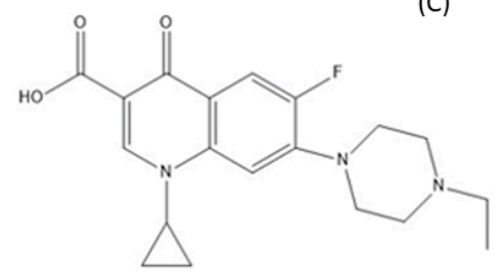

(B)<smiles>COc1cc(Cc2cnc(N)nc2N)cc(OC)c1OC</smiles>

(D)

Figure 1. Chemical structures of (A) sulfathiazole (STZ), (B) Trimethoprim (TMP) (C) enrofloxacin (ENF) and (D) erythromycin (ERM).

Monitoring antibiotics in real water samples is a real challenge due to the ultra-low concentration of the target compounds, the diversity of compounds and the high complexity of the sample matrix [22]. Therefore, before using chromatographic or hyphenated techniques sample enrichment is an essential step. The most common sample enrichment techniques to detect antibiotic residues are liquid-liquid extraction (LLE) [23,24], dispersive liquid-liquid microextraction [25,26], solid-phase extraction [27,28], solid-phase microextraction [29-31], pressurized liquid extraction [32,33], matrix solid-phase dispersion extraction [34,35], and the quick, easy, cheap, effective, rugged, and safe (QuEChERS) method [36,37]. Among these methods, SPME has gained popularity owing to its superior features such as low cost, high extractability, almost solventless uses and easy to operate technique. Previously, SPME has been applied successfully to the preconcentration of several trace antibiotic substances in water samples.

To detect several classes of an antibiotic mixture in a water environment is of prime importance that can be seen by published papers utilizing different methods. The abovementioned classes of drugs were detected individually or in combination with other classes in water samples. However, the simultaneous detection of ERF, STZ, ETM, and TMP by using SPME fiber was not reported so far.

Selection of a proper adsorbent material is of prime importance in SPME fibers to detect antibiotic compounds in water systems. In this respect, graphene is a carbon-based single-atomic-layer two-dimensional material. With different oxygen-containing functional groups, such as hydroxyl, carbonyl, carboxyl and epoxy groups on its surface and the presence of a delocalized plane $\pi$-electron system it might form strong $\pi-\pi$ bonds utilizing $\pi-\pi$ electron donor-acceptor interactions which makes 
it an ideal candidate for the detection of antibiotics [38]. Tin dioxide is a chemically stable, non-toxic, low cost, and possess high active surface area and surface to volume ratio [39]. Carbon nanotubes are an allotrope of carbon with a cylindrical nanostructure. Carbon nanotubes have a high affinity for polycyclic compounds, $\pi-\pi$ stacking capability, large surface area, and high surface that make them ideal to detect antibiotics [40]. Using multiwalled carbon nanotubes (MWCNTs) rather than single-walled carbon nanotubes (SWCNTs) offers an advantage concerning adsorption capacity due to their concentric layers of graphene [40]. Based on the favorable detection capability of GO, carbon nanotubes and $\mathrm{SnO}_{2}$, this work synthesized a composite material GCT along with biocompatible PAN that helps to stick the composite on the surface of quartz fibers to detect four classes of antibiotic in aqueous solutions.

In this present work, an analytical method based on SPME was developed to detect multiple classes of antibiotics in water. A novel and sensitive composite SPME fiber was synthesized and thoroughly characterized. The optimized extraction parameters of antibiotics from the aqueous medium were assessed and our fiber was confirmed to be much more efficient than commercial graphene, carbon nanotubes, tin dioxide, C18, polydimethylsiloxane (PDMS), and acrylate fibers. Finally, the fiber was successfully applied to detect multiple classes of antibiotic in different real aqueous environmental system.

\section{Results and Discussion}

\subsection{Characterization of GCT Hybrid Architectures}

The real challenge to bind the GCT compound onto the quartz fiber surface was solved by choosing appropriate gluing materials. The gluing material should be biocompatible and should not cover the GCT binding surface area [41]. PAN (dissolved in dimethylformamide (DMF) 1:10, v/v), was chosen as an auxiliary material due to its acid resistance and biocompatible nature [42-44]. After the third dip coating, the fiber surface was cured at $30 \mathrm{~min}$ for $120^{\circ} \mathrm{C}$; thus, the DMF was evaporated, and a porous matrix was formed on the surface of the GCT fiber. Thus, PAN not only helps to glue the GCT material but also helps form porous structures and thus provides dual characteristics $[29,41]$.

The XRD data was fitted using the JADE 6 software (6.0, Jade, Livermore, CA, USA) and the major diffraction peak was revealed to correspond to crystalline tetragonal rutile like $\mathrm{SnO}_{2}$ (JCPDS Card No. 41-1445, space group $\mathrm{P} 42 / \mathrm{mnm}, \mathrm{a} 0=\mathrm{b} 0=4.738 \AA, \mathrm{c} 0=3.187 \AA$, alpha = beta = gamma $=90.0$, volume 71.6, density 7.02). This observation (Figure $2 \mathrm{~A}$ ) was similar to the literature, thus confirming the formation of the desired compound [45].

Thermal gravimetric analysis (TGA) indicates the mass change of a material, either as a function of increasing temperature with constant heating rate, or as a function of time with constant temperature and consecutive mass loss, in an atmosphere of nitrogen, helium, air, other gas, or in a vacuum. TGA of the composite GCT material performed up to $70{ }^{\circ} \mathrm{C}$ under air indicated only one main decomposition events namely at $490^{\circ} \mathrm{C}$. From TGA analysis (Figure 2B), it is cleared that the material is stable up to $490^{\circ} \mathrm{C}$ in air, confirming its higher thermal stability.

Potassium bromide (KBr) was combined with the powder to form a pellet which spectrum was recorded by Fourier Transform Infrared spectroscopy (FT-IR) to detect the functional group of the powder. Peaks at $3300 \mathrm{~cm}^{-1}$ and $3450 \mathrm{~cm}^{-1}$ represent asymmetrical and symmetrical vibrations of amine groups (Figure 2C). The peaks at $1590 \mathrm{~cm}^{-1}$ and $1350 \mathrm{~cm}^{-1}$ were ascribed to the N-H bending vibration and C-N stretching of aromatic amines in the GCT skeleton, respectively. The peaks at $1500 \mathrm{~cm}^{-1}$ correspond to the -(O-C-O)- stretching vibration.

The zeta potential was found to be $-20.28 \mathrm{mV}$ with mobility $1.51(\mu / \mathrm{s}) /(\mathrm{V} / \mathrm{cm})$ at $\mathrm{pH} 7.4$ when dispersed in water using the Smoluchowski model (Figure S1A). The effective particle diameter of GCT was estimated to be $445.62 \mathrm{~nm}$, polydispersity 0.216 and diffusion coefficient $1.103 \mathrm{e}^{-8} \mathrm{~cm}^{2} \mathrm{~s}^{-1}$ (Figure S1B). 


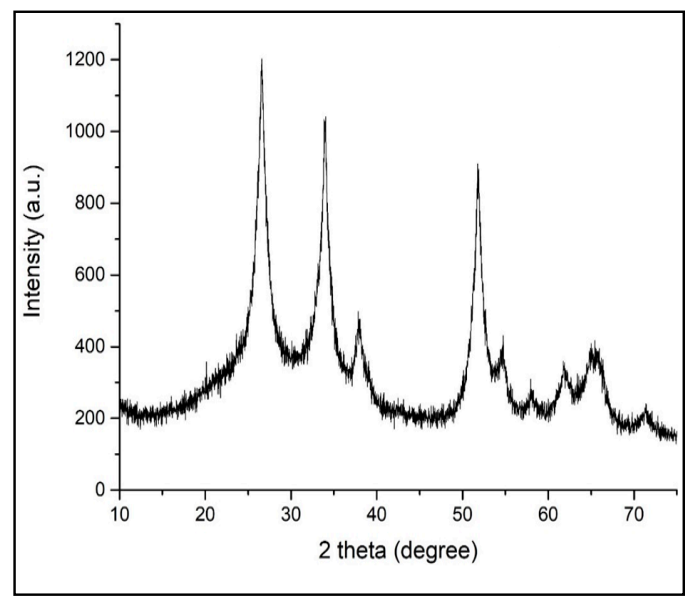

(A)

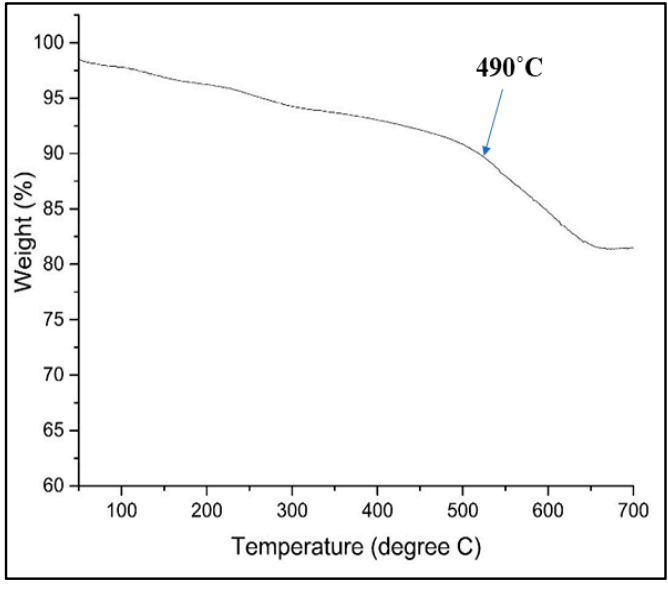

(B)

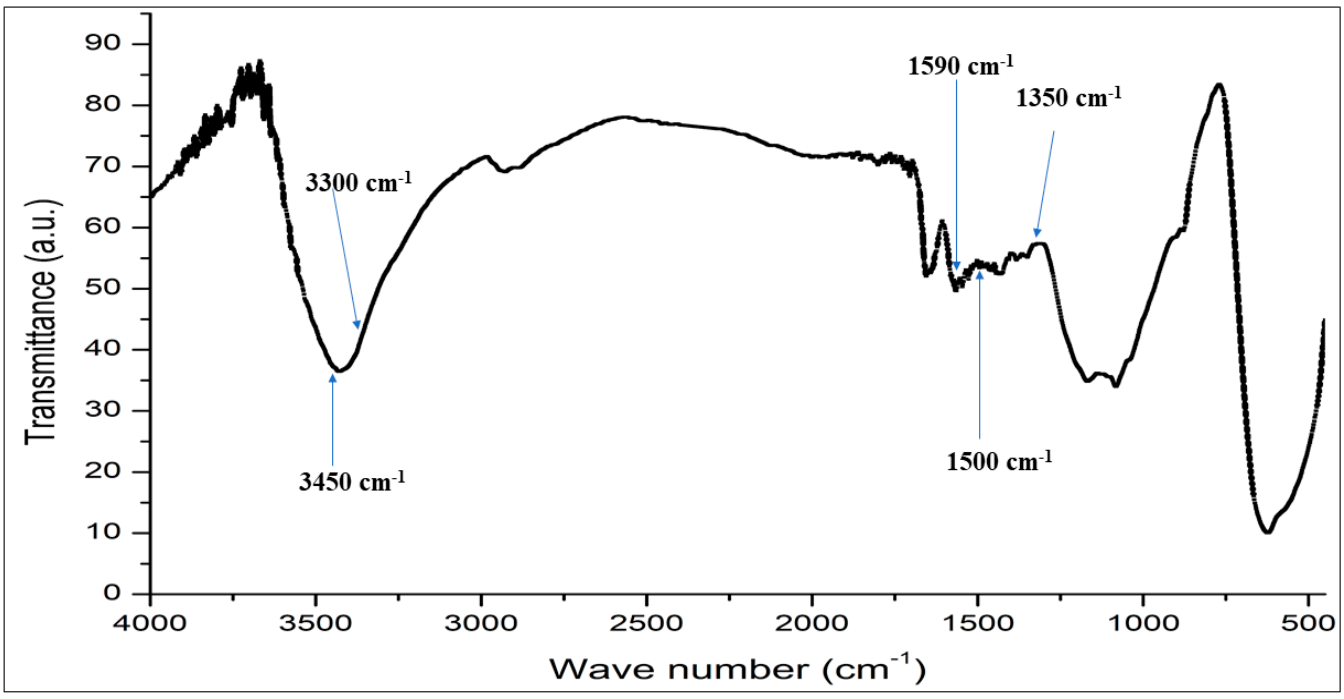

(C)

Figure 2. Image of (A) XRD, (B) TGA, and (C) FTIR images of GCT.

X-ray photoelectron spectroscopy (XPS) was used to confirm the elemental composition of the materials at the parts per thousand level. The spectra were obtained by irradiating the surfaces of powder with an X-ray beam, and the kinetic energy of the electrons released from the 0 to $10 \mathrm{~nm}$-deep surfaces of the powder was analyzed. XPS data of the powder confirms the presence of carbon, chlorine, oxygen, and tin (Figure 3A-D).

The peaks located in the $\mathrm{C}, \mathrm{O}$, and $\mathrm{Sn}$ core level regions could be assigned to $\mathrm{C} 1 \mathrm{~s}, \mathrm{O}$ 1s, and $\mathrm{Sn}$ 3d, Sn 3p, and Sn 4d, respectively (Figure S2). The deconvoluted C 1s spectrum of GCT (Figure 3A) reveals four types of carbon bonds: $\mathrm{C}=\mathrm{C} / \mathrm{C}-\mathrm{C}(284.7 \mathrm{eV}), \mathrm{C}-\mathrm{O}$ (hydroxyl and epoxy, $286.6 \mathrm{eV}), \mathrm{C}=\mathrm{O}$ (carbonyl, $287.5 \mathrm{eV}$ ), and $\mathrm{O}-\mathrm{C}=\mathrm{O}$ (carboxyl, $288.7 \mathrm{eV}$ ).

Scanning electron microscopy (SEM) analysis was carried out to examine the surface texture of GCT-coated SPME fiber. The uniform distribution of GCT material on the surface of the fiber helps to extract analytes efficiently (Figure 4A). Uniform thickness of the fiber is an important parameter to ensure the uniform extraction of analytes on the fiber surface and sensitivity of the fiber. After dipping the fiber into the PNA coating, the thickness was found to be $60 \mu \mathrm{m}$. The fiber diameter with and without material was $720 \mu \mathrm{m}$ and $660 \mu \mathrm{m}$ respectively. The SEM images of GCT powder were found to be porous, uneven and irregular shaped (Figure 4B). 


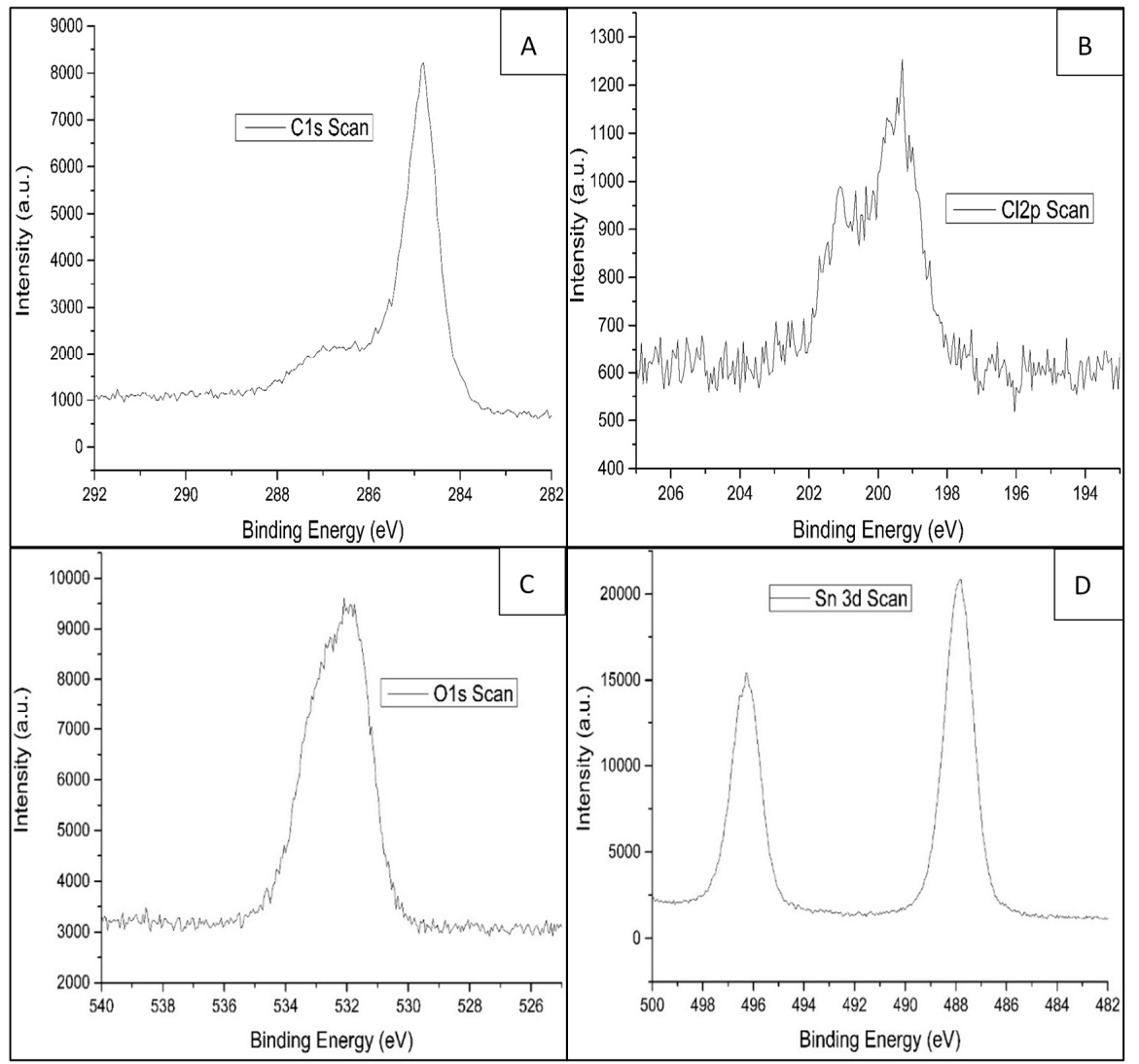

Figure 3. XPS spectra of (A) carbon, (B) chlorine, (C) oxygen, and (D) tin.

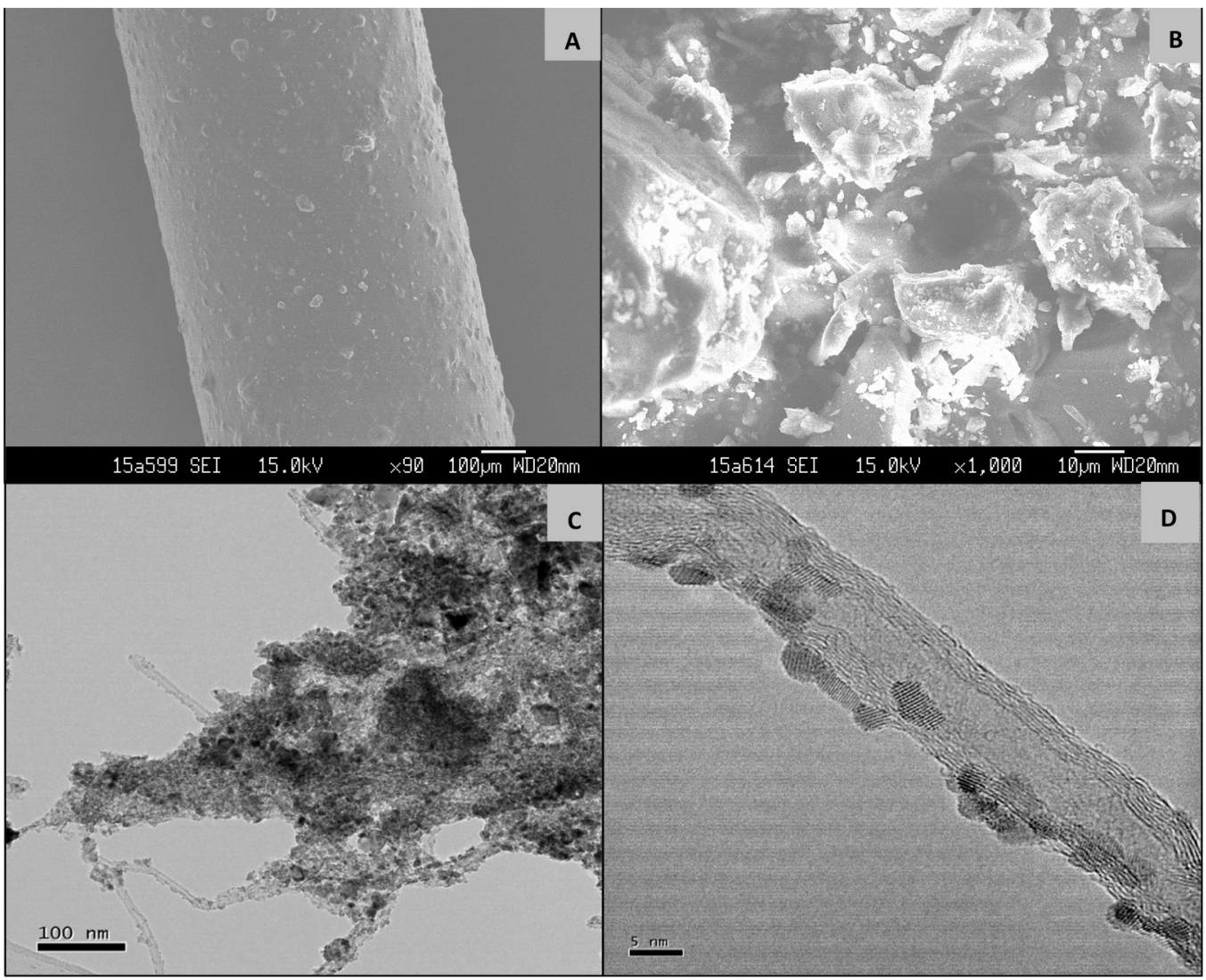

Figure 4. SEM images of GCT (A) fiber, (B) powder and TEM images of $(\mathbf{C}, \mathbf{D})$ GCT powder. 
The transmission electron microscopy (TEM) images of the GCT compound are shown in Figure 4C,D where the high-resolution TEM (HRTEM) confirms the presence of $\mathrm{SnO}_{2} \mathrm{NPs}$. The size of the NPs was $0.35 \mathrm{~nm}$ with 110 planes and $0.27 \mathrm{~nm}$ with 101 planes. The selected area electron diffraction (SAED) pattern additionally confirmed the presence of concentric circles and thick diffuse rings (Figure S3) were to be the graphene/CNTs and polycrystalline $\mathrm{SnO}_{2}$ species, respectively.

\subsection{Cost Analysis of SPME Fiber Preparation}

The cost involved in the preparation of SPME fiber through different steps, such as the cost of chemicals, equipment used, fiber cost, etc., is one of the vital facts to be taken into account to make the fiber cost-effective for its implementation in a large-scale application. Cost analyses of the preparation of SPME fibers employed for the detection of analytes are still scarce in the literature. The cost break-down for each step and the total cost for the preparation of SPME fiber in Chinese Renminbi (RMB) has been calculated in a stepwise fashion to give an idea of the approximate cost for the present investigation (Table S1). The approximate cost of an SPME fiber is found to be $6.53 \mathrm{RMB}$ or 0.97 USD, which is much more inexpensive than a commercial fiber (1000 RMB or 149 USD).

\subsection{Optimization of the GCT-PAN Hybrid Architecture Fiber Coating in Water for Antibiotics (ABs) Extraction}

In order to obtain the highest extraction of ABs from water, single-factor tests were performed to optimize different parameters such as extraction time, agitation speed, salt concentration, desorption time and solvent system for extraction and desorption. A mixture of four antibiotic compounds was spiked with a concentration of $100 \mu \mathrm{g} \mathrm{L} \mathrm{L}^{-1}$ in the optimization experiment. For each of the parameters, three parallel experiments were carried out.

\subsubsection{Extraction Time}

The extraction efficiency usually varies with extraction time as SPME is a time-dependent process where equilibrium is attained at the highest point between the donor and acceptor phases. Extraction time experiments were carried out from 5 to $75 \mathrm{~min}$ under constant experimental conditions to get the highest extraction efficiency. From Figure 5A, it was seen that the peak area of the analytes increased with increasing extraction time from 5 to $30 \mathrm{~min}$. After $30 \mathrm{~min}$, there is a negligible effect on the extraction efficacy. This phenomenon can be explained by the fact that at the beginning the GCTs active sites were vacant and the solute concentration was higher, thus attachment of $A B$ molecules on the GCT surface was increased. After a certain period, antibiotic molecules attach on all the empty places of GCT thus gave an equilibrium point. At the equilibrium point, the attachment and detachment of ABs on the surface of GCT were comparable [46]. Thus, a contact time $30 \mathrm{~min}$ was chosen as an optimum extraction time for further study.

\subsubsection{Agitation Speed}

One of the critical factors of SPME is agitation speed. Higher agitation speeds can accelerate the transfer of analyte from aqueous samples to the coating while reducing the thermodynamic equilibrium time. The effect of agitation speed was examined in the range of $300-800 \mathrm{rpm}$. It is observed from Figure $5 \mathrm{~B}$, that increasing the agitation speeds from 300 to $700 \mathrm{rpm}$ resulted in an increase in extraction efficiency, and $700 \mathrm{rpm}$ was considered the best agitation speed for the rest of the study. Further, an increase in agitation speed beyond $700 \mathrm{rpm}$ resulting in a decline of extraction efficiency due to the vigorous collision of the solution thus the formation of bubbles ultimately affecting the transfer of the analyte [47,48], so finally, $700 \mathrm{rpm}$ was chosen for further studies. 

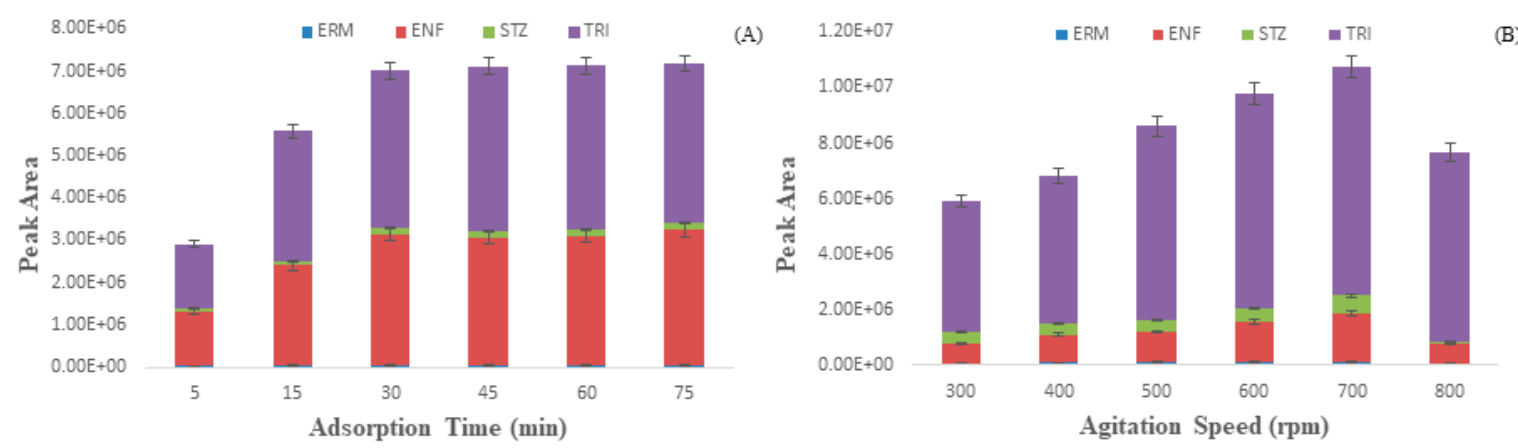

(B)
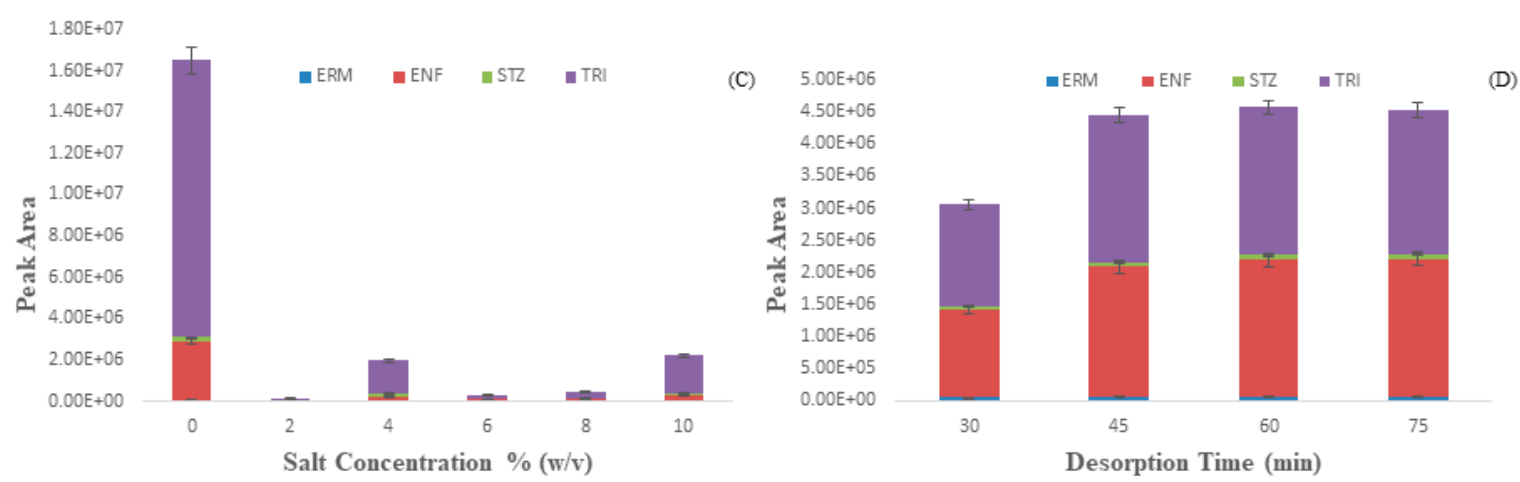

Figure 5. Effect of (A) extraction time ( $\mathrm{min}),(\mathbf{B})$ agitation speed $(\mathrm{rpm}),(\mathbf{C})$ salt conc.\% $(w / v)$ and (D) desorption time to extract Antibiotics from water.

\subsubsection{Salt Concentration}

The extraction efficiency of GCT was affected by salt concentration due to salts' salting-in and salting-out effects. While salting-in decreases the extraction efficiency, salting-out enhances the extraction efficiency $[49,50]$. The salt concentration was varied in the range of $0.0-10.0 \%(w / v)$ with intervals of $2.0 \%$ (Figure $5 \mathrm{C}$ ) while the other parameters (extraction time, $30 \mathrm{~min}$; agitation speed, $700 \mathrm{rpm}$; desorption time, $60 \mathrm{~min}$ ) were kept constant. The results evidenced that the addition of salt did not help ABs extraction due to the salting-in effect, so in the following experiments, no salt was added.

\subsubsection{Desorption Time and Solvent System}

Complete desorption is a necessary step for method sensitivity and cleansing of the fiber; therefore, desorption time is an essential parameter for the extraction of ABs. This experiment was performed to make sure no carryover (Figure S4A) was detected after fiber desorption [51,52]. Desorption time in the range of 30-75 min was investigated. Figure 5D indicated that the peak areas increased as desorption time increased from 30 to $45 \mathrm{~min}$, and further time leads to almost the same amount of peak area. Thus, 45 min was selected as the optimum desorption time for the subsequent studies.

The solubility of an antibiotic mixture in a suitable desorption solvent is an important extraction parameter as complete desorption means higher reproducibility and lesser carryover of the proposed methods [53]. In the laboratory, the two most superior solvent systems to dissolve organic compounds are methanol $(\mathrm{MeOH})$ and acetonitrile $(\mathrm{ACN})$. Three kinds of solvent system were investigated $100 \%$ $(v / v)$ methanol, 50\% (v/v) methanol/acetonitrile and 100\% (v/v) acetonitrile. From Figure S4B. It can be seen that $100 \%(v / v)$ methanol showed the highest peak area in case of most of the ABs except STZ. Therefore, $100 \%$ methanol was selected as an optimum desorption solvent in the following experiments.

\subsection{Comparison with Commercial Fibers}

The GCT fiber was first compared with the individual components of the GCT composite material. The individual component fiber was prepared with PAN in the same way as the preparation of GCT 
composite fiber. From Figure 6A, it was confirmed that the GCT fiber has more extraction efficiency than the individual components. After confirming its superiority over individual components, it was compared with different commercial fibers (Figure 6B) under its optimized conditions where it was found to be superior to C18, PDMS, or acrylate fibers regarding higher extraction efficiency. In conclusion, the GCT composite has noteworthy adsorptive capacity due to its structure and surface. The comparison of antibiotic detection by different methods has been compared with the present study (Table S2) and mostly found to be superior compared to the existing methods.

(A)

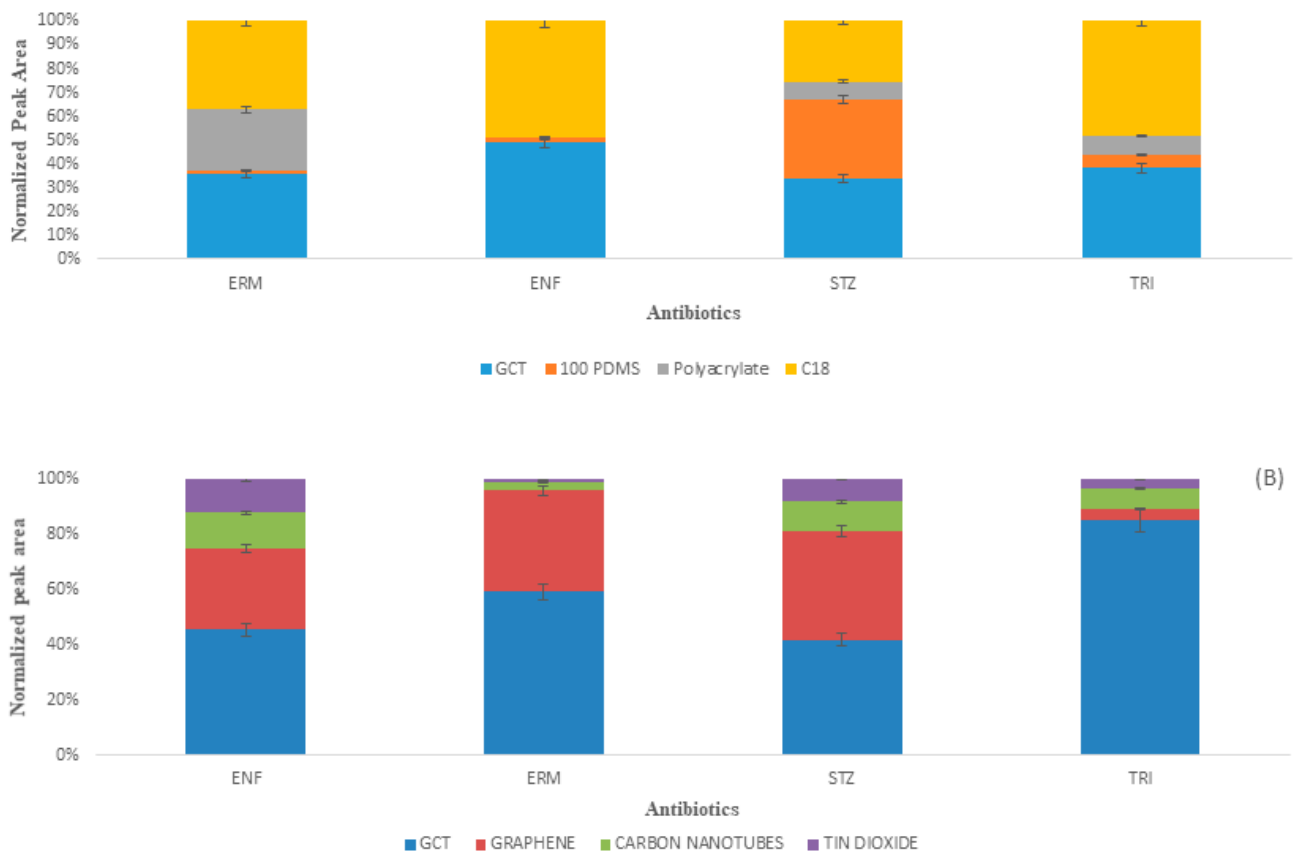

Figure 6. Comparison of extraction efficiency among (A) GCT components and with (B) different commercial fibers for the extraction of antibiotics.

\subsection{Evaluation of Method Performance}

To validate the performance of the proposed SPME procedure, a series of experiments regarding the analytical characteristics such as linearity, limit of detection (LOD), limit of quantification (LOQ), intra-batch reproducibility, batch-to-batch reproducibility and accuracy were carried out under the optimal conditions, and the results are listed in Table 1.

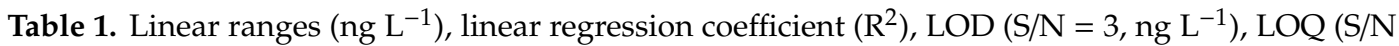
$\left.=10, \mathrm{ng} \mathrm{L}^{-1}\right)$ and intra-fiber and inter-fiber reproducibility $(\%)$ of the custom-made fiber $(n=6)$ in water sample.

\begin{tabular}{|c|c|c|c|c|c|c|}
\hline Antibiotics & $\begin{array}{l}\text { Linear Range } \\
\quad\left(\operatorname{ng~L~L~}^{-1}\right)\end{array}$ & $\mathbf{R}^{2}$ & $\begin{array}{c}\mathrm{LOD} \\
\left(\mathrm{ng} \mathrm{L^{-1 }}\right) \\
\mathrm{S} / \mathrm{N}=3\end{array}$ & $\begin{array}{c}\mathrm{LOQ} \\
\left(\mathrm{ng} \mathrm{L}^{-1}\right) \\
\mathrm{S} / \mathrm{N}=10\end{array}$ & $\begin{array}{c}\text { Intra-Fiber } \\
\text { RSD } \%\end{array}$ & $\begin{array}{c}\text { Inter-Fiber }(n=6) \\
\text { RSD } \%\end{array}$ \\
\hline ENF & $20-50000$ & 0.999 & 6.6 & 12.2 & 5.1 & 6.1 \\
\hline STZ & $20-50000$ & 0.997 & 7.69 & 15.6 & 6.8 & 8.8 \\
\hline ETM & $10-50000$ & 0.996 & 1.36 & 4.54 & 2.8 & 4.6 \\
\hline TMP & $10-50000$ & 0.998 & 0.9 & 3.02 & 1.8 & 4.5 \\
\hline
\end{tabular}

The calculated signal to noise ratios of $3(\mathrm{~S} / \mathrm{N}=3)$ and $10(\mathrm{~S} / \mathrm{N}=10)$ signify the limit of detection (LOD) and limit of quantification (LOQ), respectively [54]. The relative standard deviation (RSD) for the intra-fiber reproducibility $(n=6)$ of six sampling-desorption cycles ranged from $1.8 \%$ to $6.8 \%$, 
indicating satisfactory stability for repeated use of the custom-made fiber. Inter-fiber reproducibility was checked by the corresponding RSDs which ranged from $4.5 \%$ to $8.8 \%(n=6)$, The as-prepared fiber can be well-regenerated by dipping the fiber in methanol for $30 \mathrm{~min}$.

\subsection{Application in Real Samples}

The practical application of the proposed methods was checked by detecting trace amounts of multiple classes of ABs in three water bodies, including river, pond and tap water. Target compounds were measured according to the developed calibration curve (which were developed in milliQ water assuming the absence of matrix). Various concentrations (100.0 and $200.0 \mathrm{ng} / \mathrm{L}$ ) of each analyte were spiked into the water samples to investigate the matrix effect concerning spiked recoveries. The triplicate study evaluated the reproducibility of the spiked recoveries. From Table 2 it can be seen that the spiked recoveries varied from $81.5 \%$ to $113.3 \%$ with RSDs of 3.6 to $10.2 \%$. From the results, it can be concluded that there is no significant matrix effect and the proposed method is sensitive and reliable to simultaneously detect and quantify multiple classes of $\mathrm{ABs}$ in a complex water system.

Table 2. Concentration $\left(\mu \mathrm{g} \mathrm{L}^{-1}\right)$ and recoveries $(n=3)$ of antibiotics at different spiked levels in real environmental samples.

\begin{tabular}{|c|c|c|c|c|}
\hline Antibiotics & Detected Conc. (ng/L) & $\begin{array}{c}\text { River Water } \\
\text { Spiked Conc. }\left(\text { ng L }^{-1}\right)\end{array}$ & Recovery & RSD $\%$ \\
\hline \multirow{2}{*}{ ENF } & \multirow{2}{*}{46} & 100 & 92.14 & 9.8 \\
\hline & & 200 & 89.38 & 8.2 \\
\hline \multirow{2}{*}{ STZ } & \multirow{2}{*}{19.3} & 100 & 89.3 & 7.3 \\
\hline & & 200 & 82.1 & 4.6 \\
\hline \multirow{2}{*}{ ERM } & \multirow{2}{*}{47.2} & 100 & 113.3 & 5.8 \\
\hline & & 200 & 104.5 & 4.3 \\
\hline \multirow{4}{*}{ TMP } & \multirow{2}{*}{12.93} & 100 & 89.4 & 4.6 \\
\hline & & 200 & 89.6 & 4.8 \\
\hline & & Pond Water & & \\
\hline & Detected Conc. (ng/L) & Spiked Conc. (ng L $\left.{ }^{-1}\right)$ & Recovery & RSD $\%$ \\
\hline \multirow{2}{*}{ ENF } & \multirow{2}{*}{9.2} & 100 & 85.57 & 7.9 \\
\hline & & 200 & 87.3 & 6.9 \\
\hline \multirow{2}{*}{ STZ } & \multirow{2}{*}{13.42} & 100 & 82.7 & 4.9 \\
\hline & & 200 & 81.5 & 6.3 \\
\hline \multirow{2}{*}{ ERM } & \multirow{2}{*}{33.2} & 100 & 94.45 & 7.9 \\
\hline & & 200 & 91.68 & 7.2 \\
\hline \multirow{3}{*}{ TMP } & \multirow{2}{*}{7.29} & 100 & 90.7 & 4.1 \\
\hline & & 200 & 90.4 & 5.2 \\
\hline & Detected Conc. (ng/L) & $\begin{array}{c}\text { Tap Water } \\
\text { Spiked Conc. }\left(\mathrm{ng} \mathrm{L}^{-1}\right)\end{array}$ & Recovery & RSD\% \\
\hline \multirow{2}{*}{ ENF } & \multirow{2}{*}{ Not detected } & 100 & 84.86 & 9.7 \\
\hline & & 200 & 82.95 & 10.2 \\
\hline \multirow{2}{*}{ STZ } & \multirow{2}{*}{ Not detected } & 100 & 84.40 & 8.6 \\
\hline & & 200 & 80.34 & 8.3 \\
\hline \multirow{2}{*}{ ERM } & \multirow{2}{*}{29.5} & 100 & 95.16 & 4.2 \\
\hline & & 200 & 89.39 & 4.6 \\
\hline \multirow{2}{*}{ TMP } & \multirow{2}{*}{6.26} & 100 & 91.46 & 3.6 \\
\hline & & 200 & 90.24 & 4.3 \\
\hline
\end{tabular}

\section{Materials and Methods}

\subsection{Chemicals and Materials}

Enrofloxacin (ERF), sulfathiazole (STZ), erythromycin (ETM), trimethoprim (TMP), multiwalled carbon nanotubes and tin dichloride dihydrate $\left(\mathrm{SnCl}_{2} \cdot 2 \mathrm{H}_{2} \mathrm{O}\right)$ were purchased from Aladdin Reagent 
Company (Shanghai, China). Graphene oxide was obtained from J\&K Scientific (Beijing, China); analytical grade hydrochloric acid, sodium hydroxide, and methanol were purchased from Guangzhou Reagent Company (Guangzhou, China). Polyacrylonitrile (PAN) and HPLC grade methanol were purchased from Sigma-Aldrich Co. Ltd. (St. Louis, MO, USA). All the chemicals were used without further purification. Quartz fiber (960 $\mu$ M O.D.) were obtained from Scitlion Technology Co., Ltd (Beijing, China). Throughout the experiment ultrapure water from Merck Millipore (Burlington, MA, USA) was used. A mixture of antibiotic stock solutions (1000 and $10 \mathrm{mg} \mathrm{L}^{-1}$ ) was prepared and stored refrigerated when not in use. The working solution was made with ultrapure water by serial dilution technique before use.

\subsection{Synthesis of GCT Hybrid Architectures}

The synthesis of three-dimensional graphene oxide/carbon nanotube $/ \mathrm{SnO}_{2}$ hybrid architecture (Figure S5) was performed according to the literature with slight modifications [45]. In brief GO (20 mg) was added to ultrapure water $(20 \mathrm{~mL})$ to form a dispersion. CNTs $(10 \mathrm{mg})$ were slowly added into the GO dispersion. The mixture was then ultrasonicated for $40 \mathrm{~min}$. Afterwards, tin dichloride dihydrate $(180 \mathrm{mg}$ ) was added gradually to form a stable complex solution and stirred for $40 \mathrm{~min}$. The suspension was then sealed in a $25 \mathrm{~mL}$ Teflon-lined autoclave and kept for $12 \mathrm{~h}$ at $180^{\circ} \mathrm{C}$. After cooling, followed by centrifugation, the precipitate was collected and dried for $10 \mathrm{~h}$ at $50{ }^{\circ} \mathrm{C}$. The dried material was grounded in a pestle-mortar to prepare a small sized fine powder.

\subsection{SPME Fiber Preparation Methods}

Quartz fibers (QFs) were cut into a small piece of $3 \mathrm{~cm}$ length and sonicated in water (15 $\mathrm{min})$ and methanol ( $25 \mathrm{~min})$, respectively. Then the top of the polymer was peeled off by a metal fork, and the fiber was collected. The QF surface was neutralized by dipping in $0.1 \mathrm{M}$ sodium hydroxide followed by $0.1 \mathrm{M}$ hydrochloric acid for half an hour each stage. The QFs were dried for $12 \mathrm{~h}$. at room temperature and prepared for coating.

An excellent and equal average particle size are needed to form a uniform coating onto the surface of QFs. Therefore, small-sized fine particles of GCT were dissolved in methanol and ultrasonicated for an hour, followed by drying in an oven at $50{ }^{\circ} \mathrm{C}$.

A glue-like material was prepared to attach the GCT adsorbent onto the surface of QFs. The gluing material preparation process can briefly describe as follows: PAN $(100 \mathrm{mg})$ was dissolved in anhydrous $\operatorname{DMF}(1 \mathrm{~g})$ in a $2 \mathrm{~mL}$ Eppendorf tube. Sonication of the mixture was done for one hour to prepare a yellow colored homogeneous viscous mixture. To optimize the GCT amount, different amounts (25, 50,75 and $100 \mathrm{mg}$ ) of GCT were added to the same concentration of prepared yellow colored viscous material to form a homogenous mixture. The different mixtures were then sonicated for $1 \mathrm{~h}$ to form different dispersed slurries. The pretreated QFs were dipped in the different slurries and pulled out gradually so that a uniform layer with a length of $1 \mathrm{~cm}$ of GCT adsorbent was attached to the QF surface. This process was repeated several times until a sufficient amount of GCT was attached to the QF surface [29]. The best-optimized adsorbent was chosen according to the uniformity with the highest attachment to the QFs surface (Table S3). The best-optimized amount of GCT attached to the surface of QFs was found to be $50 \mathrm{mg}$. The self-made fiber now can be used for the quantification of pollutants in the LC-MS/MS instrument.

\subsection{Instrumentation}

TGA analysis was conducted on a TGA 2 apparatus (Mettler Toledo, Columbus, OH, USA) over a temperature range from room temperature to $800{ }^{\circ} \mathrm{C}$ at a heating rate of $15^{\circ} \mathrm{C} \mathrm{min}-1$ and under the air flow of $200 \mathrm{~mL} \mathrm{~min}^{-1}$ to check the thermal stability of the prepared adsorbent.

The X-ray diffraction (XRD) patterns eere collected on a Bruker AXS D8 advance diffraction instrument (Bruker, Karlsruhe, Germany) operating at an accelerating potential of $40 \mathrm{kV}$, tubes current of $20 \mathrm{~mA}$ and using $\mathrm{Cu} \mathrm{K} \alpha$ radiation $(\lambda=1.5406 \AA)$ at room temperature. At first, the GCT samples were 
ground to form a fine powder and scanned for $2 \mathrm{~s}$ per degree from $5-80^{\circ}$, to elucidate the crystalline structure of the samples.

After $10 \mathrm{~min}$ of incubation, the effective diameter $(\mathrm{nm})$ and zeta potential $(\mathrm{mV})$ were determined by utilizing a Brookhaven instrument (Holtsville, NY, USA). The presented data based on three independent measurements and given as mean \pm standard deviation (SD).

Scanning electron microscopy (SEM) images were recorded to see the surface morphological images of GCT on a Quanta 400 Thermal FE Environment Scanning Electron Microscope instrument (FEI/OXFORD/ HKL, Eindhoven, The Netherlands) using $20 \mathrm{kV}$.

The synthesized samples functional group and bonds were estimated by using a model IFS 66v/s IR spectrometer (Bruker). X-ray Photoelectron Spectroscopy (XPS) was performed to study the quantitative and chemical nature of the materials using an ESCALAB 250 system (Thermo Fisher Scientific, Waltham, MA, USA) with $\mathrm{Cu} \mathrm{K} \alpha$ radiation.

High-performance liquid chromatography-tandem mass spectrometry (MS/MS) was used to measure the concentration of ABs using an Agilent 1260 HPLC system (Agilent Technologies, Santa Clara, CA, USA) attached with an AB Sciex Triple Quad 4500 triple-quadrupole tandem mass spectrometer (Applied Biosystems/MDS Sciex, Framingham, MA, USA) with a dual ion mode (positive and negative) ESI source.

An Agilent Technologies Zorbax SB-C18 column was used to separate the antibiotic compounds in the HPLC system. The specifications of the column were height $150 \mathrm{~mm}$, width $2.1 \mathrm{~mm}$ and particle size $3.6 \mu \mathrm{m}$. The apparent surface area (SBET) was calculated from the $\mathrm{N}_{2}$ isotherms using the Brunauer-Emmett-Teller (BET) method.

\subsection{Instrumental Analysis}

High-performance liquid chromatography-tandem mass spectrometry (MS/MS) instrument was performed on an Agilent 1260 HPLC system (Agilent Technologies) attached to an AB Sciex Triple Quad 4500 triple-quadrupole tandem mass spectrometer with a positive and negative ion mode ESI source. The separation of analytes was done by using a Zorbax SB-C18 column $(2.1 \mathrm{~mm} \times 150 \mathrm{~mm}$, $3.6 \mu \mathrm{m}$. Heptafluorobutyric acid (0.01\%)-containing aqueous solution (A) and methanol (B) were used as mobile phases at flow rates of $300 \mu \mathrm{L} \cdot \mathrm{min}^{-1}$. The initial gradient of $100 \% \mathrm{~A}$ was ramped to $60 \% \mathrm{~A}$ in $4 \mathrm{~min}$ and kept for $3.10 \mathrm{~min}$, then ramped back to $55 \% \mathrm{~A}$ in $7.10 \mathrm{~min}$ and kept for $2 \mathrm{~min}$, then again ramped back to $25 \%, 0 \%$ and $100 \%$ with respect to time kept at $2.9 \mathrm{~min}, 0.1 \mathrm{~min}$ and $5 \mathrm{~min}$ respectively to balance the column pressure. All the transitions of ions were monitored as positive ion mode: STZ $m / z$ 255.9/107.8, TRI $m / z$ 291/123.1; ENF $m / z$ 360.1/244.8; and ERM $m / z$ 734.6/576.3. The optimum conditions for MS/MS analysis of ABs have been depicted in Table 3.

Table 3. Optimum conditions for MS/MS (ESI positive mode) analysis of antibiotics (DP: declustering potential; EP: entrance potential; CE: collision energy; CXP: collision cell exit potential. V: Volts. Da: Dalton).

\begin{tabular}{cccccccc}
\hline Antibiotics & Molecular Weight & Q1 Mass (Da) & Q3 Mass (Da) & DP (V) & EP (V) & CE (V) & CXP (V) \\
\hline Enrofloxacin & 359.39 & 360.1 & 244.8 & 116 & 11 & 33 & 17 \\
Sulfathiazole & 255.32 & 255.9 & 107.8 & 64 & 12 & 36 & 14 \\
Erythromycin & 733.93 & 734.6 & 576.3 & 164 & 12 & 29 & 30 \\
Trimethoprim & 290.32 & 291 & 230 & 70 & 7 & 34 & 9 \\
\hline
\end{tabular}

\section{Conclusions}

In this work, a GCT fiber was proposed as SPME fiber for the detection of multiple classes of ABs in aqueous systems. The structural topographical characteristics of GCT powder and its fiber were examined using XRD, TGA, FTIR, XPS, SEM, and TEM. The proposed method showed high sensitivity for most of the analytes and good reproducibility in the extraction of multiple classes of $\mathrm{ABs}$ from water. In the detection of $\mathrm{ABs}$ in a real environmental sample, this method has shown high 
recovery with good reproducibility. Moreover, as compared to commercial fiber it showed better sensitivity, lower cost, a wide linear range, and an easy preparation method, therefore, the proposed GCT fiber-based SPME-LC-MS/MS method is shown to be promising for the analysis of antibiotic mixtures in real environmental samples.

Supplementary Materials: The following are available online.

Author Contributions: Conceptualization, S.M. and G.O.; methodology, S.M.; software, S.M., J.J., Y.L.; validation, S.M. and G.O.; formal analysis, S.M., J.J., Y.L.; investigation, S.M., J.J., Y.L.; writing—original draft preparation, S.M..; writing - review and editing, S.M. and G.O.; visualization, S.M.; supervision, G.O.; project administration, S.M. and G.O.; funding acquisition, G.O.

Funding: This research was supported by projects of the National Natural Science Foundation of China (21527813, 21477166, 21677182 and 21737006), and the Natural Science Foundation of Guangdong Province (S2013030013474).

Acknowledgments: We are grateful to Fuxin Wang, Department of Chemistry, Sun Yat-Sen University, for his help in performing the TEM analysis.

Conflicts of Interest: The authors declare no conflict of interest.

\section{References}

1. Das, B.; Patra, S. Chapter 1-Antimicrobials: Meeting the Challenges of Antibiotic Resistance Through Nanotechnology. In Nanostructures for Antimicrobial Therapy; Ficai, A., Grumezescu, A.M., Eds.; Elsevier: Atlanta, GA, USA, 2017; pp. 1-22.

2. Aarestrup, F.M. The livestock reservoir for antimicrobial resistance: A personal view on changing patterns of risks, effects of interventions and the way forward. Philos. Trans. R. Soc. Lond. B Biol. Sci. 2015, 370. [CrossRef]

3. Zhang, L.; Song, X.; Liu, X.; Yang, L.; Pan, F.; Lv, J. Studies on the removal of tetracycline by multi-walled carbon nanotubes. Chem. Eng. J. 2011, 178, 26-33. [CrossRef]

4. Yu, F.; Ma, J.; Han, S. Adsorption of tetracycline from aqueous solutions onto multi-walled carbon nanotubes with different oxygen contents. Sci. Rep. 2014, 4, 5326. [CrossRef] [PubMed]

5. Tong, A.Y.C.; Peake, B.M.; Braund, R. Disposal practices for unused medications around the world. Environ. Int. 2011, 37, 292-298. [CrossRef]

6. Ji, K.; Kho, Y.; Park, C.; Paek, D.; Ryu, P.; Paek, D.; Kim, M.; Kim, P.; Choi, K. Influence of water and food consumption on inadvertent antibiotics intake among general population. Environ. Res. 2010, 110, 641-649. [CrossRef]

7. Hamscher, G.; Sczesny, S.; Höper, H.; Nau, H. Determination of Persistent Tetracycline Residues in Soil Fertilized with Liquid Manure by High-Performance Liquid Chromatography with Electrospray Ionization Tandem Mass Spectrometry. Anal. Chem. 2002, 74, 1509-1518. [CrossRef] [PubMed]

8. Kumar, A.; Pal, D. Antibiotic resistance and wastewater: Correlation, impact and critical human health challenges. J. Environ. Chem. Eng. 2018, 6, 52-58. [CrossRef]

9. Félix, L.M.; Serafim, C.; Valentim, A.M.; Antunes, L.M.; Campos, S.; Matos, M.; Coimbra, A.M. Embryonic Stage-Dependent Teratogenicity of Ketamine in Zebrafish (Danio rerio). Chem. Res. Toxicol. 2016, 29, 1298-1309. [CrossRef] [PubMed]

10. Chen, C.; Chen, Y.-C.; Hong, Y.-T.; Lee, T.-W.; Huang, J.-F. Facile fabrication of ascorbic acid reduced graphene oxide-modified electrodes toward electroanalytical determination of sulfamethoxazole in aqueous environments. Chem. Eng. J. 2018, 352, 188-197. [CrossRef]

11. Lee, H.-J.; Kim, K.Y.; Hamm, S.-Y.; Kim, M.; Kim, H.K.; Oh, J.-E. Occurrence and distribution of pharmaceutical and personal care products, artificial sweeteners, and pesticides in groundwater from an agricultural area in Korea. Sci. Total Environ. 2019, 659, 168-176. [CrossRef]

12. Xie, H.; Wang, X.; Chen, J.; Li, X.; Jia, G.; Zou, Y.; Zhang, Y.; Cui, Y. Occurrence, distribution and ecological risks of antibiotics and pesticides in coastal waters around Liaodong Peninsula, China. Sci. Total Environ. 2019, 656, 946-951. [CrossRef]

13. Kumar, M.; Jaiswal, S.; Sodhi, K.K.; Shree, P.; Singh, D.K.; Agrawal, P.K.; Shukla, P. Antibiotics bioremediation: Perspectives on its ecotoxicity and resistance. Environ. Int. 2019, 124, 448-461. [CrossRef] 
14. Davies, J.; Davies, D. Origins and evolution of antibiotic resistance. Microbiol. Mol. Biol. Rev. 2010, 74, 417-433. [CrossRef]

15. Baquero, F.; Martínez, J.-L.; Cantón, R. Antibiotics and antibiotic resistance in water environments. Curr. Opin. Biotechnol. 2008, 19, 260-265. [CrossRef]

16. Jia, W.; Chu, X.; Chang, J.; Wang, P.G.; Chen, Y.; Zhang, F. High-throughput untargeted screening of veterinary drug residues and metabolites in tilapia using high resolution orbitrap mass spectrometry. Anal. Chim. Acta 2017, 957, 29-39. [CrossRef]

17. Laxminarayan, R.; Matsoso, P.; Pant, S.; Brower, C.; Røttingen, J.-A.; Klugman, K.; Davies, S. Access to effective antimicrobials: a worldwide challenge. Lancet 2016, 387, 168-175. [CrossRef]

18. Igarashi, K.; Ishitsuka, H.; Kaji, A. Comparative studies on the mechanism of action of lincomycin, streptomycin, and erythromycin. Biochem. Biophys. Res. Commun. 1969, 37, 499-504. [CrossRef]

19. Wisell, K.T.; Kahlmeter, G.; Giske, C.G. Trimethoprim and enterococci in urinary tract infections: New perspectives on an old issue. J. Antimicrob. Chemoth. 2008, 62, 35-40. [CrossRef]

20. Papich, M.G. Enrofloxacin. In Saunders Handbook of Veterinary Drugs, 4th ed.; Papich, M.G., Ed.; W.B. Saunders: St. Louis, MO, USA, 2016; pp. 287-289.

21. Leston, S.; Nebot, C.; Nunes, M.; Cepeda, A.; Pardal, M.Â.; Ramos, F. Sulfathiazole: Analytical methods for quantification in seawater and macroalgae. Environ. Toxicol. Pharmacol. 2015, 39, 77-84. [CrossRef]

22. Ide, A.H.; Ahmad, S.M.; Neng, N.R.; Nogueira, J.M.F. Enhancement for trace analysis of sulfonamide antibiotics in water matrices using bar adsorptive microextraction (BA $\mu$ E). J. Pharm. Biomed. Anal. 2016, 129, 593-599. [CrossRef]

23. Moema, D.; Nindi, M.M.; Dube, S. Development of a dispersive liquid-liquid microextraction method for the determination of fluoroquinolones in chicken liver by high performance liquid chromatography. Anal. Chimi. Acta 2012, 730, 80-86. [CrossRef] [PubMed]

24. Wang, J.; Leung, D.; Lenz, S.P. Determination of Five Macrolide Antibiotic Residues in Raw Milk Using Liquid Chromatography-Electrospray Ionization Tandem Mass Spectrometry. J. Agric. Food Chem. 2006, 54, 2873-2880. [CrossRef] [PubMed]

25. Guan, J.; Zhang, C.; Wang, Y.; Guo, Y.; Huang, P.; Zhao, L. Simultaneous determination of 12 pharmaceuticals in water samples by ultrasound-assisted dispersive liquid-liquid microextraction coupled with ultra-high performance liquid chromatography with tandem mass spectrometry. Anal. Bioanal. Chem. 2016, 408, 8099-8109. [CrossRef] [PubMed]

26. Chen, H.; Ying, J.; Chen, H.; Huang, J.; Liao, L. LC Determination of Chloramphenicol in Honey Using Dispersive Liquid-Liquid Microextraction. Chromatographia 2008, 68, 629-634. [CrossRef]

27. Choi, K.-J.; Kim, S.-G.; Kim, C.-W.; Kim, S.-H. Determination of antibiotic compounds in water by on-line SPE-LC/MSD. Chemosphere 2007, 66, 977-984. [CrossRef]

28. Xu, J.-J.; An, M.; Yang, R.; Tan, Z.; Hao, J.; Cao, J.; Peng, L.-Q.; Cao, W. Determination of Tetracycline Antibiotic Residues in Honey and Milk by Miniaturized Solid Phase Extraction Using Chitosan-Modified Graphitized Multiwalled Carbon Nanotubes. J. Agric. Food Chem. 2016, 64, 2647-2654. [CrossRef] [PubMed]

29. Mondal, S.; Xu, J.; Chen, G.; Huang, S.; Huang, C.; Yin, L.; Ouyang, G. Solid-phase microextraction of antibiotics from fish muscle by using MIL-101(Cr)NH2-polyacrylonitrile fiber and their identification by liquid chromatography-tandem mass spectrometry. Anal. Chim. Acta 2019, 1047, 62-70. [CrossRef] [PubMed]

30. Balakrishnan, V.K.; Terry, K.A.; Toito, J. Determination of sulfonamide antibiotics in wastewater: A comparison of solid phase microextraction and solid phase extraction methods. J. Chromatogr. A 2006, 1131, 1-10. [CrossRef]

31. Reyes-Garcés, N.; Gionfriddo, E.; Gómez-Ríos, G.A.; Alam, M.N.; Boyacı, E.; Bojko, B.; Singh, V.; Grandy, J.; Pawliszyn, J. Advances in Solid Phase Microextraction and Perspective on Future Directions. Anal. Chem. 2018, 90, 302-360. [CrossRef]

32. Jiao, Z.; Zhang, S.; Chen, H. Determination of tetracycline antibiotics in fatty food samples by selective pressurized liquid extraction coupled with high-performance liquid chromatography and tandem mass spectrometry. J. Sep. Sci. 2015, 38, 115-120. [CrossRef]

33. Juan, C.; Moltó, J.C.; Mañes, J.; Font, G. Determination of macrolide and lincosamide antibiotics by pressurised liquid extraction and liquid chromatography-tandem mass spectrometry in meat and milk. Food Control 2010, 21, 1703-1709. [CrossRef] 
34. Li, M.; Sun, Q.; Li, Y.; Lv, M.; Lin, L.; Wu, Y.; Ashfaq, M.; Yu, C.-P. Simultaneous analysis of 45 pharmaceuticals and personal care products in sludge by matrix solid-phase dispersion and liquid chromatography tandem mass spectrometry. Anal. Bioanal. Chem. 2016, 408, 4953-4964. [CrossRef]

35. García-Mayor, M.A.; Gallego-Picó, A.; Garcinuño, R.M.; Fernández-Hernando, P.; Durand-Alegría, J.S. Matrix solid-phase dispersion method for the determination of macrolide antibiotics in sheep's milk. Food Chem. 2012, 134, 553-558. [CrossRef]

36. Yu, X.; Liu, H.; Pu, C.; Chen, J.; Sun, Y.; Hu, L. Determination of multiple antibiotics in leafy vegetables using QuEChERS-UHPLC-MS/MS. J. Sep. Sci. 2018, 41, 713-722. [CrossRef] [PubMed]

37. He, Z.; Wang, Y.; Xu, Y.; Liu, X. Determination of Antibiotics in Vegetables Using QuEChERS-Based Method and Liquid Chromatography-Quadrupole Linear Ion Trap Mass Spectrometry. Food Anal. Methods 2018, 11, 2857-2864. [CrossRef]

38. Katsnelson, M.I. Graphene: carbon in two dimensions. Mater. Today 2007, 10, 20-27. [CrossRef]

39. Marikutsa, A.; Rumyantseva, M.; Gaskov, A. Selectivity of Catalytically Modified Tin Dioxide to CO and NH3 Gas Mixtures. Chemosensors 2015, 3, 241-252.

40. Zhao, H.; Liu, X.; Cao, Z.; Zhan, Y.; Shi, X.; Yang, Y.; Zhou, J.; Xu, J. Adsorption behavior and mechanism of chloramphenicols, sulfonamides, and non-antibiotic pharmaceuticals on multi-walled carbon nanotubes. J. Hazard. Mater. 2016, 310, 235-245. [CrossRef]

41. Chen, G.; Qiu, J.; Xu, J.; Fang, X.a.; Liu, Y.; Liu, S.; Wei, S.; Jiang, R.; Luan, T.; Zeng, F.; et al. A novel probe based on phenylboronic acid functionalized carbon nanotubes for ultrasensitive carbohydrate determination in biofluids and semi-solid biotissues. Chem. Sci. 2016, 7, 1487-1495. [CrossRef]

42. Vuckovic, D.; Risticevic, S.; Pawliszyn, J. In Vivo Solid-Phase Microextraction in Metabolomics: Opportunities for the Direct Investigation of Biological Systems. Angew. Chem. Int. Ed. 2011, 50, 5618-5628. [CrossRef]

43. Vuckovic, D.; Pawliszyn, J. Systematic Evaluation of Solid-Phase Microextraction Coatings for Untargeted Metabolomic Profiling of Biological Fluids by Liquid Chromatography-Mass Spectrometry. Anal. Chem. 2011, 83, 1944-1954. [CrossRef] [PubMed]

44. Cudjoe, E.; Bojko, B.; de Lannoy, I.; Saldivia, V.; Pawliszyn, J. Solid-Phase Microextraction: A Complementary In Vivo Sampling Method to Microdialysis. Angew. Chem. Int. Ed. 2013, 52, 12124-12126. [CrossRef] [PubMed]

45. Zhang, Z.; Wang, L.; Xiao, J.; Xiao, F.; Wang, S. One-Pot Synthesis of Three-Dimensional Graphene/Carbon Nanotube/SnO2 Hybrid Architectures with Enhanced Lithium Storage Properties. ACS Appl. Mater. Interfaces 2015, 7, 17963-17968. [CrossRef] [PubMed]

46. Mondal, S.; Aikat, K.; Halder, G. Biosorptive uptake of ibuprofen by chemically modified Parthenium hysterophorus derived biochar: Equilibrium, kinetics, thermodynamics and modeling. Ecol. Eng. 2016, 92, 158-172. [CrossRef]

47. Wang, X.; Sheng, W.-R.; Jiao, X.-Y.; Zhao, R.-S.; Wang, M.-L.; Lin, J.-M. Zinc(II)-based metal-organic nanotubes coating for high sensitive solid phase microextraction of nitro-polycyclic aromatic hydrocarbons. Talanta 2018, 186, 561-567. [CrossRef] [PubMed]

48. Wang, X.; Wang, H.; Huang, P.; Ma, X.; Lu, X.; Du, X. Preparation of three-dimensional mesoporous polymer in situ polymerization solid phase microextraction fiber and its application to the determination of seven chlorophenols. J. Chromatogr. A 2017, 1479, 40-47. [CrossRef]

49. Grundl, G.; Müller, M.; Touraud, D.; Kunz, W. Salting-out and salting-in effects of organic compounds and applications of the salting-out effect of Pentasodium phytate in different extraction processes. J. Mol. Liq. 2017, 236, 368-375. [CrossRef]

50. Gao, J.; Huang, C.; Lin, Y.; Tong, P.; Zhang, L. In situ solvothermal synthesis of metal-organic framework coated fiber for highly sensitive solid-phase microextraction of polycyclic aromatic hydrocarbons. J. Chromatogr. A 2016, 1436, 1-8. [CrossRef]

51. Chen, J.; Pawliszyn, J.B. Solid Phase Microextraction Coupled to High-Performance Liquid Chromatography. Anal. Chem. 1995, 67, 2530-2533. [CrossRef]

52. Jinno, K.; Taniguchi, M.; Hayashida, M. Solid phase micro extraction coupled with semi-microcolumn high performance liquid chromatography for the analysis of benzodiazepines in human urine. J. Pharm. Biomed. Anal. 1998, 17, 1081-1091. [CrossRef] 
53. Tang, Y.; Xu, J.; Chen, L.; Qiu, J.; Liu, Y.; Ouyang, G. Rapid in vivo determination of fluoroquinolones in cultured puffer fish (Takifugu obscurus) muscle by solid-phase microextraction coupled with liquid chromatography-tandem mass spectrometry. Talanta 2017, 175, 550-556. [CrossRef] [PubMed]

54. Khan, R.; Ben Aissa, S.; Sherazi, A.T.; Catanante, G.; Hayat, A.; Marty, L.J. Development of an Impedimetric Aptasensor for Label Free Detection of Patulin in Apple Juice. Molecules 2019, 24, 1017. [CrossRef] [PubMed]

Sample Availability: Samples of the compounds GCT are available from the authors.

(C) 2019 by the authors. Licensee MDPI, Basel, Switzerland. This article is an open access article distributed under the terms and conditions of the Creative Commons Attribution (CC BY) license (http://creativecommons.org/licenses/by/4.0/). 